\title{
Clitoria ternatea ethanolic extract prevents dental caries via inhibiting Streptococcus mutans growth and quorum sensing
}

\author{
${ }^{1,2 *}$ Yanti, ${ }^{1}$ Setiawan, T. and ${ }^{1,2}$ Lay, B.W. \\ ${ }^{1}$ Faculty of Biotechnology, Atma Jaya Catholic University of Indonesia, Jakarta 12930, Indonesia \\ ${ }^{2}$ Research Center for Indonesian Spices, Atma Jaya Catholic University of Indonesia, Jakarta 12930, \\ Indonesia
}

\begin{abstract}
Article history:
Received: 12 September 2020 Received in revised form: 27 October 2020

Accepted: 17 December 2020 Available Online: 30 April 2021
\end{abstract}

Keywords:

Clitoria ternatea ethanolic extract,

Antibacterial activity,

Antiquorum sensing activity, Dental caries

DOI:

https://doi.org/10.26656/fr.2017.5(2).508

\begin{abstract}
Our previous study demonstrated that the blue butterfly pea flower (Clitoria ternatea) had several pharmacological effects to treat inflammatory-related diseases, including edema and diabetes. However, its benefit for preventing dental caries and protecting the tooth has not been explored yet. Here, we investigated whether C. ternatea ethanolic extract (CTEE) prevented dental caries through antibacterial and antiquorum sensing activities toward oral pathogen Streptococcus mutans in vitro. CTEE was made by using kinetic maceration in ethanol. Antibacterial activity of CTEE against $S$. mutans was tested using disk diffusion agar and microdilution assays. Quorum sensing system employed Chromobacterium violaceum bacteria to produce violacein, and CTEE at various concentrations was tested for its antiquorum sensing activity to inhibit the violacein production. Our results demonstrated that CTEE at $1 \mathrm{mg} / \mathrm{mL}$ showed a significant inhibition $>90 \%$ against $S$. mutans, indicating its MIC value. For the quorum sensing system, CTEE at the lowest concentration $(0.25 \mathrm{mg} / \mathrm{mL})$ significantly inhibit up to $68 \%$ of violacein produced by $C$. violaceum. These data indicate that CTEE may act as a natural oral functional food with antibacterial and antiquorum sensing activities for the prevention of dental caries.
\end{abstract}

\section{Introduction}

Dental caries is the most common infectious disease in the world. This disease is caused by food consumption, oral bacteria, and tooth morphology (Ozdemir, 2014). Streptococcus mutans is known to be a major causative organism for dental caries and has the ability for utilizing carbohydrates in organic acids. These bacteria increase antibacterial resistance by colonizing tooth surface and forming a distinctive extracellular polymeric matrix network. This dental biofilm formation can lead to the development of oral infectious diseases, such as caries, gingivitis and periodontitis (Decker et al., 2014). The common treatment of dental caries was done by tooth restoration, however, this method does not stop the caries process, and requires restoration and ongoing maintenance throughout life. Antibacterial agents can be employed for protection and treatment against oral diseases. In fact, some reports indicated that these agents caused a toxic reaction and increased the resistance mechanism against oral pathogens. Thus, improved diagnosis, prevention, and early management of dental caries are needed to combat this disease (Ozdemir,
2014).

Research in oral medicine from natural products is important to be explored in order to prevent and cure dental caries. Natural products from various medicinal plants have been recognized for their potential antibacterial activities with novel mechanisms that are more effective and less toxic (Bhalodia and Shukla, 2011). The butterfly pea flower (Clitoria ternatea) is a plant that originated from the Molucca Islands in Indonesia and belongs to Fabaceae family. The blue flower of C. ternatea is rich in flavonoids (anthocyanin, ternatin, delphinidin, quercetin, kaempferol, catechin, epicatechin, preternatin, syringetin, and myrisetin), organic acids (acetate acid, galat acid, chlorogenic acid), and protein (Kazuma et al., 2013; Neda et al., 2013; Azima et al., 2017; Chayaratanasin et al., 2019; Minelko et al., 2020; Yanti et al., 2020). It is known that this plant has been used for culinary and folk medicine in Asia regions, including Indonesia and India. In India, the C. ternatea flower has been traditionally used as part of Ayurvedic medicine. Our previous study demonstrated that the ethanolic extract of $C$. ternatea blue flower 
(CTEE) exerted anti-inflammatory effects for the treatment of edema in the animal model (Yanti et al., 2020). CTEE was able to act as an anti-inflammatory agent by reducing the edema volume in carragenaninduced rat paw edema by attenuating the expression of several genes related to phosphoinositide 3 kinase signalling pathway. The in silico study by Wijaya et al. (2020) resulted in the potency of anthocyanin and ternatin found in CTEE for the treatment of inflammatory diseases by conducting molecular docking analysis. Anthocyanin and ternatin are known as the major pigment compounds in CTEE were able to bind with several pro-inflammatory ligands, including inducible nitric oxide synthase (iNOS), cyclooxygenase (COX)-2, and myeloperoxidase (MPO). In a recent report, protein extracted from $C$. ternatea possessed an antidiabetic effect by inhibiting alpha-glucosidase activity and lowering blood glucose in alloxan-induced mice (Minelko et al., 2020). In this report, the efficacy CTEE in preventing dental caries against $S$. mutans oral pathogen by testing its antibacterial and antiquorum sensing activities in vitro was investigated.

\section{Materials and methods}

\subsection{Preparation of C. ternatea ethanolic extract}

The dried $C$. ternatea flower was obtained from a local farm in Bogor (West Java province, Indonesia). Extraction of $C$. ternatea flower was prepared according to the method of Seo et al. (2014). Dried C. ternatea flower $(0.5 \% \mathrm{w} / \mathrm{v})$ was diluted in $70 \%$ ethanol and kinetically macerated by heating at $50^{\circ} \mathrm{C}$ for an hour. The solution was filtered and concentrated by using a rotary evaporator at $60^{\circ} \mathrm{C}$, followed by freeze-drying overnight. The extract was obtained and stored at $-18^{\circ} \mathrm{C}$. The extract yield was calculated using this formula: Yield $(\%)=($ Initial sample weight sample + final sample weight)/Initial sample weight) $\times 100 \%$. The yield of CTEE was $34.12 \%$.

\subsection{Preparation of bacteria and bacterial growth}

S. mutans (ATCC 25175) was cultured in Brain Heart Infusion Agar (BHIA) at $37^{\circ} \mathrm{C}$ and incubated overnight. For the antibacterial assay, the inoculum was diluted in the sterile saline solution until the concentration of $1 \times 10^{8} \mathrm{CFU} / \mathrm{mL}$ was achieved. Then, the inoculum was diluted with BHI broth until the concentration of $2 \times 10^{5} \mathrm{CFU} / \mathrm{mL}$ was reached.

\subsection{Antibacterial activity assay}

Antibacterial assays of CTEE against $S$. mutans were done by using agar disk diffusion and microdilution methods (Kalia et al., 2015; Balouiri et al., 2016). For agar disk diffusion assay, $S$. mutans was growth in BHIA and blank disks were placed on the surface. A $50 \mu \mathrm{L}$ of CTEE and tetracycline standard at $2 \mathrm{mg} / \mathrm{mL}$ were added into the blank disks, followed by incubation at $37^{\circ} \mathrm{C}$ for overnight. The inhibition zone was measured (in $\mathrm{mm}$ ). For microdilution assay, CTEE was firstly diluted in DMSO $10 \%$ for obtaining final concentrations at a range of $0.06-2 \mathrm{mg} / \mathrm{mL}$. A $100 \mu \mathrm{L}$ CTEE at various concentrations was added into a 96-well plate, followed by the addition of $100 \mu \mathrm{L} S$. mutans inoculum into each well plate. Tetracycline standard $(2 \mathrm{mg} / \mathrm{mL})$ was used as a positive control, while negative control was a $200 \mu \mathrm{L}$ BHIB without CTEE. The plate was incubated at $37^{\circ} \mathrm{C}$ overnight. Bacteria growth was measured at $595 \mathrm{~nm}$ using a macroplate reader. The minimum inhibitory concentration (MIC) value is defined as the lowest concentration of CTEE that completely inhibits $>90 \%$ of $S$. mutans growth. Bacterial growth inhibition was calculated as follow: Antibacterial activity $(\%)=($ AcAs/Ac) $\times 100 \%$, where Ac is the absorbance of the negative control and as is the absorbance of the CTEE sample.

\subsection{Antiquorum sensing activity assay}

Quorum sensing inhibitory assay of CTEE was done by employing Chromobacterium violaceum (ATCC 12472) according to the method of Choo et al. (2006). $C$. violaceum was grown in Luria Bertani (LB) broth and incubated at $37^{\circ} \mathrm{C}$ overnight. For analysis, the bacterial strain was inoculated in an Erlenmeyer flask containing LB broth, LB broth supplemented with CTEE (0.25-4 $\mathrm{mg} / \mathrm{mL}$ ), and LB broth with tetracycline standard (2 mg/ $\mathrm{mL}$ ). All flasks were incubated at $27^{\circ} \mathrm{C}$ in an incubator shaker $(150 \mathrm{rpm})$ overnight. One $\mathrm{ml}$ of culture from each flask was centrifuged at $13.000 \times g$ for $10 \mathrm{mins}$ to precipitate the insoluble violacein. The culture supernatant was discarded and one ml of DMSO 100\% was added to the pellet. The solution was mixed for 30 seconds until violacein was soluble and centrifuged at $13.000 \times \mathrm{g}$ for 10 mins to remove the debris cells. A 200 $\mu \mathrm{L}$ of supernatant containing violacein was added to a 96 -well microplate. The absorbance was measured at 585 $\mathrm{nm}$ using a macroplate reader. $C$. violaceum in LB broth was used as negative control and $C$. violaceum in LB broth with tetracycline standard was used as a positive control. Antiquorum sensing activity of CTEE was expressed as absorbance percentage of the remained violacein compared with that of the negative control.

\subsection{Statistical analysis}

All experiments in this study were done in triplicate. Data were expressed as mean and standard deviation (SD). The results were computed by one-way ANOVA 
using IBM SPSS Statistics 24.0. $P<0.05$ was considered to indicate statistical significance.

\section{Results and discussion}

\subsection{Antibacterial activity of CTEE}

Preliminary antibacterial screening of CTEE against $S$. mutans using disk diffusion agar assay showed that CTEE caused a clear zone around the disk (Figure 1, left). This indicates that CTEE exerted an antibacterial effect to inhibit the growth of S. mutans. Similar efficacy was also shown by the tetracycline standard. Furthermore, the antibacterial activity of CTEE was tested quantitatively by using a microdilution assay. Our results demonstrated that CTEE at various concentrations $(0.06-2 \mathrm{mg} / \mathrm{mL})$ significantly inhibited $>70 \%$ of $S$. mutans growth (Figure 1, right). MIC value of CTEE was reached at a concentration of $1 \mathrm{mg} / \mathrm{mL}$, while tetracycline standard had MIC and MBC values at a concentration of $2 \mathrm{mg} / \mathrm{mL}$.

S. mutans is one of the human oral colonizing bacteria is used as a model for dental caries. S. mutans is a facultative anaerobe and gram-positive coccus bacterium that has the ability to metabolize various carbohydrates into organic acids which may cause destruction of tooth surface and lead to dental caries. C. ternatea flower is believed to have potency as a novel natural oral medicine to combat dental caries due to its various active compounds (Jeon et al., 2011). Profiling of phytoconstituents in C. ternatea showed that this plant rich in primary and secondary metabolites such as tannins, phlobatannin, carbohydrates, saponins, triterpenoid, phenols, flavonoids, flavonol glycosides, proteins, alkaloids, antharaquinones, anthocyanins, cardiac glycosides, volatile oils, and steroids (Gupta, et al., 2010; Al-Snafi, 2016). These substances may have potential as promising natural oral medicine against dental caries.

In this study, CTEE at $1 \mathrm{mg} / \mathrm{mL}$ showed MIC value against $S$. mutans (Figure 1). It is assumed that CTEE has the ability as a novel antibacterial agent against oral pathogen $S$. mutans due to its secondary metabolite contents, such as phenolic acids, anthraquinones, flavonoids, tannins, terpenoids, and alkaloid that have been proven to inhibit bacterial growth. These compounds have actions as antibacterial agents by targetting bacterial viability to be killed via disrupting cell wall biosynthesis and cell membrane permeability, complexing with surface-adsorbed components, and inhibiting protein synthesis. All these factors are generally not selective for specific species and have a broad spectrum of antibacterial effects (Jeon et al., 2011). A previous study by Rukayadi and Hwang (2006) demonstrated that xanthorrhizol, a sesquiterpenoid compound isolated from Java turmeric, also exerted antibacterial effect against $S$. mutans. A similar study by Widyarman et al. (2018) demonstrated that C. ternatea flower juice prevented dental caries by inhibiting the formation of Porphyromonas gingivalis dental plaque and killing the existed $P$. gingivalis biofilms.

\subsection{Antiquorum sensing activity of CTEE}

In the quorum sensing system, we employed $C$. violaceum strain to study the capability of CTEE to inhibit the quorum sensing by reducing violacein production. C. violacuem is a gram-negative bacterium that is able able to produce the purple pigment of violacein as quorum sensing result by using autoinducer $\mathrm{N}$-hexanoyl homoserine lactone. This autoinducer will produce and secrete into the environment and diffuse back to bacteria when the quorum happens. Autoinducer will bind transcription regulator CviR and participate in specific gene expression like violacein (Choo et al., 2006). Nowadays, searching for natural antiquorum sensing agents with reduced or absent side effects becomes the focus of the investigation. In the quorum sensing model, the percentage of violacein produced by C. violaceum indicated the actual action of the sample for blockage or killing the bacteria (Abudoleh and Mahasneh, 2017). The use of violacein quantification assay for determining the quorum sensing inhibition by the natural agents may give various results depending on the extracting solvent, type of the producer bacteria, and the concentration of the substances. It is known that quorum sensing inhibition is an alternative way for pathogen control through manipulation of gene
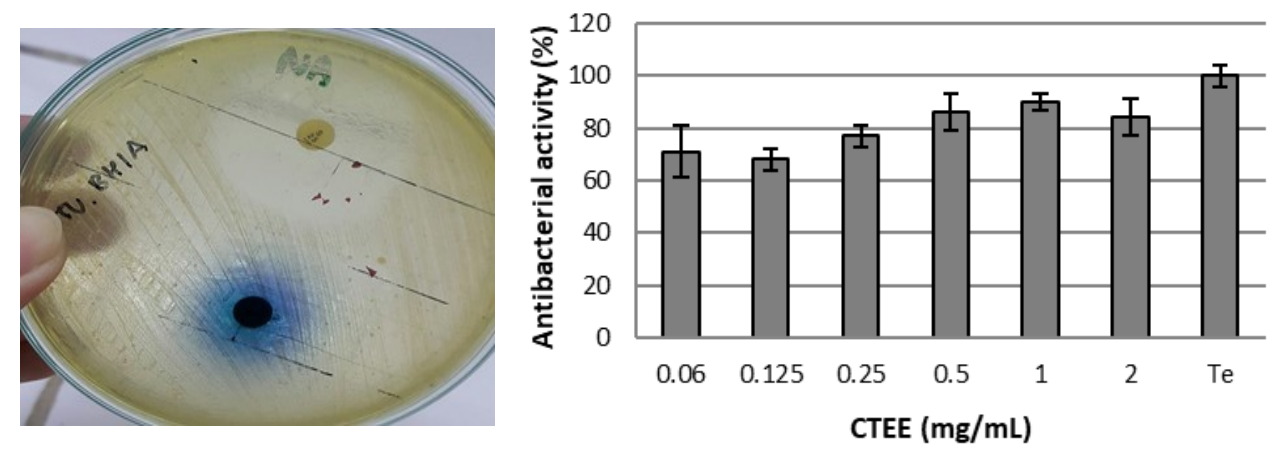

Figure 1. Antibacterial activity of CTEE against $S$. mutans by agar disk diffusion (left) and microdilution (right) assays. Left: a, CTEE (2 $\mathrm{mg} / \mathrm{mL})$ and $\mathrm{b}$, tetracycline standard $(2 \mathrm{mg} / \mathrm{mL})$. Right: tetracycline standard $(\mathrm{Te}, 2 \mathrm{mg} / \mathrm{mL})$ was used as a positive control. Error bars indicate mean \pm SD. All data were statistically significant differences $(P<0.05)$. 
expression rather than killing the pathogen. The utilization of natural quorum sensing inhibitor may offer an alternative strategy for combating emerging resistant pathogenic bacteria.

Our results demonstrated that CTEE at $0.25 \mathrm{mg} / \mathrm{mL}$ significantly reduced violacein production up to $68 \%$ (Figure 2). Interestingly, its inhibitory efficacy was higher than the tetracycline standard $(2 \mathrm{mg} / \mathrm{mL})$. CTEE contained various polar constituents, including primary and secondary metabolites. The use of ethanol solvent and the degree of sample purity may be associated with the amount and type of compounds extracted from $C$. ternatea blue flower. We assume that at the lowest concentration $(0.25 \mathrm{mg} / \mathrm{mL})$, most compounds in CTEE may act synergistically for inhibiting $>60 \%$ of violacein produced by $C$. violaceum compared to that of high dose of CTEEs and tetracycline standard. As this is the first report about the potency of CTEE as a natural antiquorum sensing candidate, thus, it is necessary to conduct a further study using some purified compounds derived from CTEE for investigating which compound is exactly responsible for antiquorum sensing action.

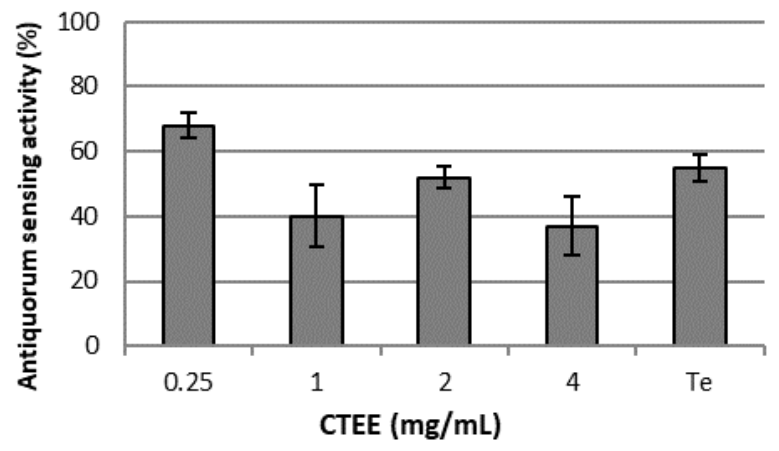

Figure 2. Antiquorum sensing activity of CTEE at various concentrations by using violacein quantification assay. Tetracycline standard (Te, $2 \mathrm{mg} / \mathrm{mL}$ ) was used as a positive control. Error bars indicate mean $\pm \mathrm{SD}$. All data were statistically significant differences $(\mathrm{P}<0.05)$.

Previous studies demonstrated the use of tetracycline and other commercial antibiotics for investigating their potency as inhibitors on quorum sensing (Skindersoe et al., 2008; Deryabin and Inchagova, 2018). Tetracycline is reported to exert quorum sensing inhibitory effect with moderate action. It is noted that tetracycline and its derivatives are well known as antibacterial agents with broad-spectrum. Due to the resistance of antibiotic use, novel screening for alternative natural antiquorum sensing agents from plants and microorganisms has been the focus of research investigation. To present, there is no commercial drug standard for quorum sensing inhibitors. Some reports recommended the utilization of antibiotics, like kanamycin, gentamycin, amikacin, tetracycline, and doxycycline for quorum sensing inhibitory model (Deryabin and Inchagova, 2018).
Quorum sensing is cell to cell communication that control bacteria physiological (Choo et al., 2006). This mechanism uses small diffusible molecules (autoinducers) that secreted, detected, and respond by bacteria and has an important role in bacterial infection. In comCDE quorum sensing system, the relation between bacteriocin production, stress response, genetic competence, and biofilm formation was important for virulence factor in S. mutans ( $\mathrm{Li}$ and Tian, 2012). Moreover, quorum quenching also offers an alternative control strategy for diseases caused by bacterial infection. Quorum quenching may prevent the expression of virulence factors of pathogenic bacteria rather than preventing cell growth. Quorum quenching system could be used to resolve antibiotic toxicity, severe infection, and antibiotic resistance problem due to its ability to destroy pathogen sensors against cell density and inhibit the ability to trigger virulence expression (Chen et al., 2013). This ability also ensure the host to have time against natural pathogen with normal immune system function. Thus, the quorum quenching system is run by controlling host-microbial activity and quorum sensing.

It has been known that several bacterial phenotypes, including virulence, biofilm maturation, secondary metabolite production, plasmid transfer, bioluminescence, and motility are under the control of quorum sensing (Ceylan et al., 2014). Our results revealed that CTEE at the lowest dose significantly inhibited $>60 \%$ of violacein produced by $C$. violaceum (Figure 2), indicating its potential antiquorum sensing activity in the reporter $C$. violaceum strain. Other reports by Choo et al. (2006) confirmed that vanilla extract at 1 and $2 \%$ exerted inhibitory activity up to $87.73 \%$ and $98.41 \%$ against $C$. violaceum quorum sensing.

The quorum sensing system of $S$. mutans is induced by interaction with diverse members of the oral microbiome. S. mutans quorum sensing is a mechanism for adjusting its phenotype to the presence and activity of the oral microbiome. S. mutans could kill their competitors and use their DNA for genetics adaptation that provides a powerful survival mechanism in the complex community (Szafranski et al., 2017). Based on our findings, CTEE as a novel quorum sensing inhibitor might be assumed to eliminate the ability of $S$. mutans to adapt and defend themself. Hence, the possibility of dental caries caused by $S$. mutans can be prevented.

\section{Conclusion}

These data suggest that CTEE could prevent dental caries by inhibiting $S$. mutans growth and quorum sensing activities. CTEE could be applied for oral care functional foods and oral health care product as an 
alternative therapeutic strategy for combating dental caries. Further study is needed to determine which compound in CTEE is exactly responsible for exhibiting dual antibacterial and antiquorum sensing actions.

\section{Conflict of interest}

The authors declared there is no conflict of interest. The authors alone are responsible for the content of the paper.

\section{Acknowledgement}

This research was funded by the Decentralization Grant from General Directorate of Higher Education, Ministry of Research, Technology and Higher Education, Republic of Indonesia.

\section{References}

Abudoleh, S.M. and Mahasneh, A.M. (2017). Antiquorum sensing activity of substances isolated from wild berry associated bacteria. Avicenna Journal of Medical Biotechnology, 9(1), 23-30.

Al-Snafi, A.E. (2016). Pharmacological importance of Clitoria ternatea - A review. IOSR Journal of Pharmacy, 6(3), 68-83.

Azima, A.M.S., Noriham, A. and Manshoor, N. (2017). Phenolics, antioxidants and color properties of aqueous pigmented plant extracts: Ardisia colorata var. elliptica, Clitorea ternatea, Garcinia mangostana and Syzygium cumini. Journal of Functional Foods, 38(part A), 232-241. https:// doi.org/10.1016/j.jff.2017.09.018

Balouiri, M., Sadiki, M. and Ibnsouda, S.K. (2016). Methods for in vitro evaluating antimicrobial activity: A review. Journal of Pharmaceutical Analysis, 6(2), 71-79. https://doi: 10.1016/ j.jpha.2015.11.005.

Bhalodia, N.R. and Shukla, V.J. (2011). Antibacterial and antifungal activities from leaf extracts of Cassia fistula 1: An ethnomedicinal plant. Journal of Advanced Pharmaceutical Technology and Research, 2(2),104-109. https:// doi.org/10.4103/2231-4040.82956

Ceylan, O., Ugur, A. and Sarac, N. (2014). In vitro antimicrobial, antioxidant, antibiofilm and quorum sensing inhibitory activities of Bellis perennis L. Journal of BioScience and Biotechnology, 2014, 3542.

Chayaratanasin, P., Caobi, A., Suparpprom, C., Saenset, S., Pasukamonset, P., Suanpairintr, N., Barbieri, M.A. and Adisakwattana, S. (2019). Clitoria ternatea flower petal extract inhibits adipogenesis and lipid accumulation in 3T3-L1 preadipocytes by downregulating adipogenic gene expression. Molecules, 24(10), 1894. https://doi:10.3390/ molecules24101894

Chen, F., Gao, Y., Chen, X. and Li, X. (2013). Quorum quenching enzymes and their application in degrading signal molecules to block quorum sensing -dependent infection. International Journal of Molecular Sciences, 14(9), 17477-17500. https:// doi:10.3390/ijms140917 477.

Choo, J.H., Rukayadi, Y. and Hwang, J.K. (2006). Inhibition of bacterial quorum sensing by vanilla extract. Letters in Applied Microbiology, 42(6), 637641. https://doi: 10.1111/j.1472-765X.2006.01928.x.

Decker, E.M., Klein, C., Schwindt, D. and Ohle, C. (2014). Metabolic activity of Streptococcus mutans biofilm and gene expression during exposure to xylitol and sucrose. International Journal of Oral Science, 6(4), 195-204. https://doi:10.1038/ ijos.2014.38.

Deryabin, D.G. and Inchagova, K.S. (2018). Inhibitory effect of aminoglycosides and tetracyclines on quorum sensing in Chromobacterium violaceum. Microbiology, 87, 1-8. https://doi.org/10.1134/ S002626171801006X

Gupta, G.K., Chahal, J. and Bhatia, M. (2010). Clitoria ternatea (L.): old and new aspects. Journal of Pharmacy Research, 3(1), 2610-2614.

Jeon, J.G., Rosalen, P.L., Falsetta, M.L. and Koo, H. (2011). Natural products in caries research: current (limited) knowledge, challenges and future perspective. Caries Research, 45(3), 243-263. https://doi: 10.1159/000327250.

Kalia, M., Yadav, V.K., Singh, P.K., Sharma, D., Pandey, H. and Narvi, S.S. (2015). Effect of cinnamon oil on quorum sensing-controlled virulence factors and biofilm formation in Pseudomonas aeruginosa. PLoS ONE, 10(8), e0135495. https://doi:10.1371/journal.pone.0135495.

Kazuma, K., Noda, N. and Suzuki, M. (2003). Flavonoid composition related to petal color in different lines of Clitoria ternatea. Phytochemistry, 64(6), 11331139. https://doi.org/10.1016/S0031-9422(03)005041

Li, Y.H. and Tian, X. (2012). Quorum sensing and bacterial social interactions in biofilm. Sensors (Basel), 12(3), 2519-2538. https://doi:10.3390/s120 302519.

Minelko, M., Gunawan, A.G., Ali, S., Suwanto, A. and Yanti. (2020). Protein extracted from Clitoria ternatea modulates genes related to diabetes in vivo. International Food Research Journal, 27(4), 610- 
617.

Neda, G.D., Rabeta, M.S. and Ong, M.T. (2013). Chemical composition and anti-proliferative properties of flowers of Clitoria ternatea. International Food Research Journal, 20(3), 12291234.

Ozdemir, D. (2014). Dental caries and preventive strategies. Journal of Educational and Instructional Studies in the World, 4(4), 20-24.

Rukayadi, Y. and Hwang, J.K. (2006). In vitro activity of xanthorrhizol against Streptococcus mutans biofilms. Letters in Applied Microbiology, 42(4), 400-404. https://doi: $\quad 10.1111 /$ j.1422-7642-765X.2006.0187 6.x.

Seo, J., Lee, S., Elam, M.L., Johnson, S.A., Kang, J. and Arjamandi, B.H. (2014). Study to find the best extraction solvent for use with guava leaves (Psidium guajava L.) for high antioxidant efficiency. Food Science and Nutrition, 2(2), 174-180. https:// doi: $10.1002 / \mathrm{fsn} 3.91$.

Skindersoe, M.E., Alhede, M., Phipps, R., Yang, L., Jensen, P.O., Rasmussen, T.B., Bjarnsholt, T., Tolker-Nielsen, T., Høiby, N. and Givskov, M. (2008). Effects of antibiotics on quorum sensing in Pseudomonas aeruginosa. Antimicrobial Agents and Chemotherapy, 52(10), 3648-3663. https:// doi.org/10.1128/AAC.01230-07.

Szafranski, S.P., Deng, Z.L., Tomasch, J., Jarek, M., Bhuju, S., Rohde, M., Sztajer, H. and WagnerDobler, I. (2017). Quorum sensing of Streptococcus mutans is activated by Aggregatibacter actinomycetemcomitans and by the periodontal microbiome. BMC Genomics, 18, 238. https://doi: 10.1186/s12864 -017-3618-5.

Widyarman, A.S., Sumadi, S. and Agustin, T.P. (2018). Antibiofilm effect of Clitoria ternatea flower juice on Porphyromonas gingivalis in vitro. Journal of Indonesian Dental Association, 1(1), 7-12. https:// doi.org/10.32793/jida.v1i1.288

Wijaya, Y.T., Yulandi, A., Gunawan, A.W. and Yanti. (2020). In silico study of anthocyanin and ternatin flavonoids for the treatment of inflammation-related diseases using molecular docking analysis. Food Research, 4(3), 780- 785. https://doi.org/10.26656/ fr.2017.4(3).378

Yanti, Sabella, D., Gunawan, A.W. and Lay, B.W. (2020). Clitoria ternatea anthocyanin extract suppresses inflammation in carrageenan-induced rat PAW edema via down-regulating genes of phosphoinositide 3-kinase signaling pathway. Food Research, 4(4), 1357-1362. https://doi.org/10.26656/ fr.2017.4(4).028 